\title{
La gestión indirecta de los servicios públicos locales *
}

\author{
Isabel María de los Mozos Touya \\ Profesora Titular de Derecho Administrativo \\ Universidad de Valladolid
}

\begin{abstract}
SUMARIO: I. EL CONTRATO DE GESTIÓN DE SERVICIOS PÚBLICOS EN EL ÁMBITO LOCAL: A) Su objeto: los servicios públicos locales (servicio al público; servicio esencial —obligatorio y/o mínimo-y servicio reservado). B) Sus condicionantes: la asunción de la actividad y los principios sobre el régimen de su gestión. C) Sus modalidades (en particular, el problema de la distinción entre la concesión y el arrendamiento). II. LOS CONVENIOS.
\end{abstract}

Como es sabido, para el cumplimiento de sus fines y en interés público, las Entidades locales deben llevar a cabo una actividad de prestación de servicios, dirigidos a la colectividad local. Se trata de la necesidad —o también la conveniencia - de prestar diferentes servicios de distinta importancia, pero todos ellos de interés local, como el abastecimiento de agua potable, la recogida de basuras, el transporte de viajeros, la oferta de actividades culturales y deportivas, o el mantenimiento de parques y jardines, entre otros.

Para realizar estas prestaciones, en unos casos, las Entidades locales recurren a la contratación con otros sujetos jurídicos, constituyendo contratos administrativos y contratos interadministrativos, que responden a lo que se denomina gestión indirecta, por cuanto la Entidad local presta un servicio al público recurriendo a otro sujeto, que será el gestor del servicio, en virtud de un contrato.

En otros casos, las Entidades locales realizan sus prestaciones al público directamente, a través de la llamada gestión directa que no excluye, sin embargo, que también pueda resultar implicado en la prestación del servicio otro sujeto distinto de la Entidad local competente para ello. Con todo, la relación jurídica que se establece entonces entre ambos sujetos no es contractual, sino de pura dependencia instrumental y organizativa, que responde a la llamada descentralización funcional o por servicios en unas

\footnotetext{
* Este trabajo tiene su origen en una conferencia pronunciada en Gerona, durante el curso 2001/2002, en el marco de las Jornadas de Derecho Local, organizadas por la Universidad Autónoma de Barcelona, la Diputación de Gerona y la Generalidad de Cataluña, cuyo texto está ya en prensa a cargo de la Fundación Caixa de Girona, al que se han añadido aquí algunas referencias nuevas.
} 
ocasiones y, en otras, a la formalización jurídico-privada de una actividad empresarial pública.

No debe olvidarse que esto último puede suponer también una manifestación más del fenómeno de la huida del Derecho administrativo, en los casos en que la actividad prestacional en cuestión, o no se desarrolla en régimen de competencia (por ejemplo, las sociedades mercantiles de suministro de agua), o no es auténticamente mercantil (por no ofrecer ningún servicio al mercado como, por ejemplo, las sociedades mercantiles de recaudación pública).

Frente a la gestión directa, como ya se ha indicado, la gestión indirecta de los servicios públicos se caracteriza y define por la presencia ineludible en ella de un contrato, que suele ser precisamente el genérico contrato administrativo de gestión de servicios públicos, regulado en el Texto Refundido vigente de la Ley de Contratos de las Administraciones Públicas, aprobado por el Real Decreto Legislativo 2/2000 ${ }^{1}$, que tiene carácter básico en lo dispuesto íntegramente por sus artículos 154 a 158, 160 a 162, 164 y 170, así como por lo dispuesto en parte de sus artículos 159 y 169 .

Asimismo, a la gestión indirecta pueden referirse también los convenios interadministrativos de cooperación (o contratos públicos en sentido estricto, según la terminología acuñada en su día por el Prof. ENTRENA Cuesta) ${ }^{2}$, a éstos se les podrá aplicar también la Ley de Contratos, aunque sólo sea con carácter supletorio, por razón de lo dispuesto en su artículo 3; sobre ellos y su normativa se volverá brevemente más adelante.

Para completar, negativamente, el panorama global de la gestión indirecta, baste con aludir a las fundaciones privadas de la Ley estatal 30/1994, en cuanto pretendida modalidad de gestión indirecta de los servicios públicos locales ${ }^{3}$, que nada tienen que ver con la figura de las antiguas Fundaciones públicas de servicios (rebautizadas más tarde como Organismos Autónomos locales que, como es sabido, son una forma de gestión directa). Además, tales fundaciones privadas tampoco encajan entre los contratos típicos de gestión de servicios públicos, ni la Ley que las regula

\footnotetext{
${ }^{1}$ No tienen carácter básico el resto de los preceptos que lo regulan en dicho Texto Refundido y, en concreto, los contenidos en los arts.163 y 165 a 168 .

2 Vid. Rafael Entrena Cuesta, «Consideraciones sobre la teoría general de los contratos de la Administración», en Revista de Administración Pública, 24 (1957), p. 73.

${ }^{3}$ Vid., en ese sentido, sin embargo, F. Sosa WAGner, Manual de Derecho local, Aranzadi, Pamplona 2000, p. 235.
} 
se refiere expresamente a dicha gestión, por lo que no deben ser consideradas como una modalidad más de la gestión indirecta.

La utilización instrumental de estas fundaciones privadas por el sector público ha sido denunciada por la doctrina ${ }^{4}$, por plantear serios problemas de constitucionalidad y supone, además de otro caso de huida del Derecho administrativo $^{5}$, una tergiversación de la propia institución fundacional ${ }^{6}$. Por otra parte, el derecho de fundación proclamado por el artículo 34 de la Constitución parece reconocido más en favor de los ciudadanos que de los Poderes públicos, si nos atenemos a su ubicación sistemática dentro del texto constitucional ${ }^{7}$.

I.- Delimitado así el ámbito propio de la gestión indirecta y por lo que se refiere a los contratos de gestión de los servicios públicos locales, es necesario precisar cuál es su objeto, para aludir después a sus condicionantes y a sus modalidades.

A) Para determinar el objeto de estos contratos, convendrá precisar qué se entiende específicamente por servicio público en la legislación básica y general de contratos de las Administraciones públicas y en la legislación local. Se puede entender, así, que del mismo modo que la legislación básica de contratos ${ }^{8}$, la legislación local acoge también un concepto amplio de

\footnotetext{
${ }^{4}$ Vid., en este sentido, J. L. MARTínEZ LóPEZ-MuÑIZ, «Fundaciones privadas del sector público: problemas de constitucionalidad», en S. Martín-Retortillo y J. Tornos Mas (Edes.), La Enseñanza del Derecho Administrativo. Tercer Sector y Fundaciones. Rutas Temáticas e Itinerarios Culturales (XIII Congreso italo-español de Profesores de Derecho Administrativo, Salamanca, octubre del 2000), Cedecs, Barcelona 2002, pp. 301-332.

${ }^{5}$ Vid. J. C. Laguna De Paz, «La renuncia de la Administración Publica al Derecho Administrativo», en Revista de Administración Pública, 136 (1995), pp. 201-229.

${ }^{6}$ Según ha denunciado también la doctrina civilista, vid., en este sentido, J. L. DE LOS Mozos Y DE Los Mozos, «Sistema de reconocimiento de la fundación en sus límites naturales», en Congreso de Academias Jurídicas Iberoamericanas, Real Academia de Jurisprudencia y Legislación-Fundación Ramón Areces, Madrid 1998, pp. 486-489.

${ }^{7}$ El único derecho de los reconocidos en esa misma sección segunda del capítulo segundo, del título I de la Constitución (derechos y deberes de los ciudadanos), que por su naturaleza es predicable también de los Poderes públicos, es el derecho a la herencia (que puede reconocerse a cualquier persona, física o jurídica, pública o privada), ya que el derecho de propiedad privada, en cuanto tal, no parece que deba corresponder a las Entidades públicas, como lo demuestra el hecho de que la llamada propiedad privada de las Entidades públicas sea contemplada, bajo la denominación de bienes patrimoniales, en otro precepto constitucional (art. 132.3), a pesar de la conocida redacción del art. 339 del Código Civil.

${ }^{8}$ Vid. J.J. LaVilla RubIRA, «El contrato de gestión de servicios públicos», en Comentario a la Ley de Contratos de las Administraciones Públicas (Dir. Rafael Gómez-Ferrer), Civitas, Madrid 1996, p. 758 .
} 
servicio público ${ }^{9}$, en cuanto actividad prestacional pública ejercida en el ámbito propio de las competencias locales.

1. En tal sentido, el artículo 85.1 de la Ley $7 / 1985$ dispone:

«1. Son servicios públicos locales cuantos tienden a la consecución de los fines señalados como de la competencia de las Entidades locales».

Se trata, pues, de servicios dirigidos al público que se relacionan con cualquiera de las materias sobre las que cada Municipio ejerce sus competencias (excepto las que supongan ejercicio de autoridad) ${ }^{10}$, en los términos de la legislación del Estado y de las Comunidades Autónomas, con arreglo a lo dispuesto por el artículo 25 de la Ley básica local (y por otros preceptos concordantes, como el art. 63.2 de la Ley catalana de régimen local) ${ }^{11}$. La amplitud del concepto explica que los servicios públicos locales puedan referirse tanto a actividades libres, como a actividades publificadas o reservadas a la titularidad pública, como se expondrá un poco más adelante.

En todo caso, junto a este concepto amplio de servicio público, o servicio al público - en el que encajan desde las prestaciones culturales y deportivas, hasta los servicios funerarios, pasando por los transportes urbanos, el abastecimiento de agua potable o la extinción de incendios-, la legislación local ha acogido también un concepto algo más preciso de servicio público, que es el de servicio esencial.

2. En efecto, al servicio esencial se refiere a la legislación local, cuando establece los llamados servicios obligatorios (en el art. 26 de la Ley básica local y en el art. 64 de la Ley catalana). Se trata de servicios que el legislador ha querido destacar como especialmente necesarios para la colectividad local y, por ello, en unos casos serán obligatorios en todos los municipios [como los servicios mínimos previstos por el art. 26.1,a) de la Ley básica local y por el art. 64,a) de la Ley catalana] y, en otros, lo serán en función del número de sus habitantes (el resto de los servicios obligatorios). Se podrá objetar que la esencialidad es un concepto material que puede no coincidir con la obligatoriedad, pero se podrá convenir también en que ésta es —en todo caso- la traducción jurídica de aquélla.

\footnotetext{
${ }^{9}$ Ese me parecía también el significado de la acepción de servicio público, que se contenía en la legislación de contratos anterior a la Ley 13/1995, cuya reforma ha dado lugar al Texto Refundido vigente; vid. I. DE LOS Mozos TouYa, Educación en libertad y concierto escolar, Montecorvo, Madrid 1995, p.400.

${ }^{10}$ Según se establece en el propio art. 85.2.

${ }^{11}$ Cfr. la Ley Municipal y de Régimen Local de Cataluña (L. 8/1987, de 15 de abril).
} 
En primer lugar, los servicios esenciales son universales en el sentido expuesto por MARTínEZ LóPEZ-MuÑIZ ${ }^{12}$, porque son obligatorios. Es decir, la Entidad local deberá asegurar que las prestaciones en que consistan lleguen a todos por igual; $\mathrm{y}$, cuando tienen contenido económico, coinciden además con los servicios de interés económico general, según la terminología del artículo 86.2 del Tratado de la Comunidad Europea, que los somete a las reglas de la competencia siempre que ello no impida el cumplimiento de su misión específica.

Este criterio del servicio universal fundamenta también el actual artículo 73 del Tratado constitutivo que, desde un principio, ha permitido excepcionalmente las transferencias financieras públicas que correspondan al reembolso de determinadas obligaciones inherentes a la noción de servicio público en el sector del transporte. Tales obligaciones son aquéllas que se exijan con carácter singular a los operadores del sector para asegurar, en su caso, la universalidad de sus prestaciones ${ }^{13}$.

En segundo lugar, la naturaleza de estos servicios, esa esencialidad, o «misión específica» que tengan encomendada, puede constituir un indicio de por qué no se sujetan los contratos de gestión de servicios públicos a las Directivas comunitarias sobre contratación pública. Pues, esa misión específica puede venir reservada a la titularidad pública en algunos Estados miembros, generando así derechos especiales o exclusivos, al margen de la competencia, en favor de los operadores de los sectores de actividad implicados. Y esa reserva se justifica por excepción en el Derecho comunitario originario, precisamente, en razón de su esencialidad y consiguiente universalidad (siempre que ello no resulte contrario al interés de la Comunidad) ${ }^{14}$.

3. Esto último nos lleva ya al concepto de servicio esencial reservado por Ley a las Entidades locales, del artículo 86.3 de la Ley básica local y del artículo 228 de la Ley catalana. Estos servicios locales esenciales y reservados se refieren a las actividades que han resultado publificadas por la Ley básica (en aplicación del art. 128.2 de la Constitución) y que, por

\footnotetext{
12 Vid. J. L. Martínez LóPeZ-MuÑIZ, «Servicio público, servicio universal y «obligación de servicio público» en la perspectiva del Derecho Comunitario: los servicios esenciales y sus regímenes alternativos», en Revista Andaluza de Administración Pública, 39 (2000), pp. 43-49; y en Os caminhos da privatizaçáo da Administraçáo pública (IV Colóquio luso-aspanhol de Direito administrativo), Universidade de Coimbra, 2001, pp. 268-275.

${ }^{13}$ Vid. I. DE Los Mozos TouYA, «Obligaciones especiales de servicio público en el transporte rural», en Revista de Estudios de la Administración Local y Autonómica, 282 (2000), pp. 119-156.

${ }^{14}$ En los términos dispuestos por el propio art. 86.2, in fine, del Tratado constitutivo de la Comunidad Europea.
} 
ello, han sido sustraidas a la iniciativa privada (en la línea apuntada por Gómez-Ferrer y Gallego Anabitarte ${ }^{15}$, aunque en el marco de lo dispuesto por el art. 26), en la medida en que tales actividades se refieran a servicios esenciales - y obligatorios, por ello, en cada caso (según el nivel demográfico de la Entidad)—, como se explica a continuación.

Es decir, que, de este modo, la efectividad de esa reserva de actividad (con el consiguiente régimen de monopolio) sólo será posible y exigible, cuando el servicio correspondiente sea obligatorio con respecto a una determinada Entidad local, según su nivel de población y con arreglo a lo dispuesto por el citado artículo 26. Esto es así, en la medida en que los servicios esenciales pueden identificarse en la Ley básica local, con los que se declaran en ella como obligatorios. Así sucede, por ejemplo, en todo caso, con servicios como el de abastecimiento domiciliario de agua potable y el de recogida de residuos, que son obligatorios en todos los Municipios, porque la Ley los considerarse esenciales con independencia del número de habitantes de la Entidad.

Por el contrario, cuando se trate de servicios no obligatorios ${ }^{16}$, la Entidad local no podrá hacer efectiva su reserva mediante el expediente de monopolización. Porque ello chocaría con el propio artículo 128.2 de la Constitución, cuando establece que se podrán reservar servicios esenciales (mediante ley). El motivo de esa vulneración estaría en que la reserva prevista por la ley básica local no puede ser inmediata, ya que está condicionada en su aplicación a circunstancias cambiantes de las que depende, además, la exigencia constitucional misma de que se trate de servicios esenciales. Tales circunstancias son el nivel de población que, según la misma Ley, determina en cada caso cuáles son los servicios esenciales y, por ello, obligatorios ${ }^{17}$.

Así, cuando la doctrina se ha referido a que del artículo 86.3 cabe deducir una reserva «diferida o latente» ${ }^{18}$, en favor de las Entidades locales, a

15 Vid. R. GómEZ-FerRer MoRANT, «La reserva al sector público de recursos o servicios esencia-
les», en Estudios sobre la Constitución española (Homenaje al Profesor Eduardo García de Ente-
rría), V, Civitas, Madrid 1991, pp. 3821-3822. También, A. GALLEGo ANABITARTE, «Actividades y
servicios municipales. Competencia municipal general o según Ley. Una controversia», Estudio
Preliminar a la obra de J. ORTEGa Bernardo, Estado, Comunidades Autónomas y Corporaciones
Locales ante la gestión de los residuos urbanos, Pons, Madrid 2003, p. 23 .

${ }^{16}$ En la medida en que — por ello mismo - no son considerados como esenciales por la Ley, con respecto a esa determinada población.

${ }^{17}$ No estaría suficientemente justificado que se monopolizaran servicios que no hubiesen sido declarados por la propia ley básica local como esenciales, en cuanto obligatorios en cada caso.

18 Vid., por todos, J. M. DíAz Lema, Los monopolios locales, Montecorvo, Madrid 1994, pp. 77 y ss. 
las que habilita para que efectivamente puedan aplicar o no dicha reserva, sin ningún límite expreso, por lo expuesto anteriormente, me parece que en este punto se ha minusvalorado el posible juego de la obligatoriedad dispuesta por el citado artículo 26. Porque la efectividad de la reserva del artículo 86.3 sólo será, constitucionalmente, posible y exigible cuando se refiera a servicios esenciales y por ello obligatorios ${ }^{19}$, a medida que éstos vayan surgiendo en función de los cambios de población y pueda, entonces, hacerse efectiva esa reserva.

Por todo ello, en el ámbito propio de las actividades «genéricamente reservadas» por la ley básica local, los servicios públicos correspondientes, mientras no sean obligatorios (ni se consideren legalmente como esenciales, por tanto), deberán ser prestados en concurrencia con la iniciativa privada, porque no podrán ser monopolizados. Esto puede explicar, quizás, por ejemplo, que el artículo 229 de la Ley catalana disponga que los servicios esenciales, reservados por ley a la Entidad local, podrán ser prestados en régimen de libre concurrencia y, además, en régimen de monopolio ${ }^{20}$ (en ambos casos, se dispone, que a través de cualquiera de las formas de gestión establecidas legalmente) ${ }^{21}$.

De lo expuesto hasta aquí se desprende que el objeto del contrato de gestión de servicio público en el ámbito local consiste en cualquier servicio dirigido al público, esencial o no, reservado o no, cuya prestación haya sido asumida por una Entidad local y, en consecuencia, ofrecido a otros sujetos para su prestación por medio de un contrato.

B) Esta caracterización del objeto del contrato de gestión de servicios públicos en el ámbito local, nos remite necesariamente a la previa asunción de la correspondiente actividad prestacional, por parte de la Administración titular del servicio y en razón de sus competencias. Hoy se puede entender que los términos de municipalización o de provincialización, en su caso, aluden a esa asunción de actividad que, junto con la elección de la forma de gestión indirecta frente a la directa, constituyen los condicionamientos propios del contrato de gestión de servicios públicos.

\footnotetext{
${ }^{19} \mathrm{Vid}$., en contra, J.M. Díaz Lema, ibid., p. 61; donde, al sostener que es irrelevante que estemos ante servicios obligatorios o facultativos a efectos de la reserva, afirma: «en ambos casos, el legislador permite al Ayuntamiento la implantación del monopolio».

${ }^{20} \mathrm{~A}$ medida que sean obligatorios y pueda entonces hacerse efectiva la reserva, mediante el expediente de monopolización.

${ }^{21}$ Cfr. del mismo modo, el art. 162.1 de su Reglamento de obras, actividades y servicios, aprobado por Decreto 179/1995.
} 
1. Haciendo un análisis desprovisto de prejuicios doctrinales y liberado del peso de los muchos argumentos de autoridad que unos y otros esgrimen en este ámbito, sobre la base del Reglamento estatal de Servicios de las Corporaciones locales de 1955, se podrá aceptar que, en la legislación anterior a la vigente Ley básica local, la municipalización equivalía a la gestión directa de los servicios públicos locales y, según se desprende de dicho Reglamento estatal, esa gestión directa de actividades podría tener lugar con monopolio (lo que implicaba reserva de actividad) o sin él (lo que implicaba concurrencia de la gestión directa con la iniciativa privada).

Hoy, sin embargo, la municipalización no es más que la asunción de una actividad prestacional por el Municipio que, del mismo modo, podrá tener lugar con monopolio o sin él ${ }^{22}$, en el marco de la Ley básica y con arreglo a lo ya expuesto. Así se desprende del artículo 47.3,f) de la Ley 7/1985, al referirse a la necesidad de una mayoría cualificada (absoluta) de los miembros de la Corporación, para adoptar los acuerdos de municipalización o de provincialización de actividades «en régimen de monopolio», así como para la aprobación de la forma concreta de su gestión.

Dicho precepto quiere decir, a contrario, que cabe también la municipalización sin monopolio, lo cual implicará que la Entidad asuma una actividad prestacional en concurrencia con la privada. Asimismo, el citado precepto significa también que las actividades municipalizadas, cuando sean ejercidas en régimen de monopolio (es decir, en el marco de la publicatio o reserva pública de la titularidad de la actividad), podrán ser prestadas de forma directa o indirecta. Y esto será así, sin perjuicio de que las actividades no publificadas o libres, cuyo ejercicio deba asumir la Entidad local necesariamente en concurrencia, por tanto, puedan ser prestadas también de ambas formas, con arreglo a lo dispuesto con alcance general por el artículo 85.2 de la Ley básica local, cuando dispone:

«Los servicios públicos locales pueden gestionarse de forma directa o indirecta. En ningún caso podrán prestarse por gestión indirecta los servicios públicos que impliquen ejercicio de autoridad».

2. Con todo, de la legislación cabe deducir un criterio preferencial en favor de la gestión indirecta, para determinar la elección de la forma de gestión de los servicios públicos locales; dicho criterio se apoya en el reconocimiento de, al menos, dos principios jurídico-públicos destacables: el

\footnotetext{
${ }^{22}$ Vid., en otro sentido, sobre la municipalización, J. L. Rivero Ysern, Manual de Derecho Local, Civitas, Madrid 1999, pp. 383-384.
} 
principio pro libertate y el principio de subsidiariedad entendido en su sentido horizontal.

Sobre la base del artículo 30 del Reglamento de Servicios de 1955 (recogido hoy en el art. 230.1 de la Ley local catalana), la doctrina ha subrayado que la elección de la forma de gestión del servicio es una manifestación de la potestad auto-organizatoria de cada Entidad ${ }^{23}$, como establece expresamente el artículo 233 de la propia Ley catalana (así como el art. 188.4 de su Reglamento de obras, actividades y servicios). Pues bien, aunque esto sea así, la legislación local $-\mathrm{y}$ los principios que la sustentan- delimitan, como también se viene afirmando ${ }^{24}$, esa potestad electiva de las Entidades locales (que es expresión de su autonomía).

En primer lugar, con respecto al principio pro libertate, se podrá entender que éste se traduce en la preferencia de la gestión indirecta frente a la directa, sobre la base de lo dispuesto en el ya citado artículo 85.2 de la Ley básica local y en otros preceptos concordantes (como el art. 155.1 del Texto Refundido de la Ley de Contratos de las Administraciones Públicas, el art. 95.1 del Real Decreto Leg.781/1986 o el ya citado art. 233 de la Ley local catalana), cuando en ellos se establece que los servicios públicos locales podrán gestionarse directa o indirectamente, con el único límite de aquellos servicios que impliquen ejercicio de autoridad, que sólo podrán gestionarse directamente.

Ante estos preceptos, a primera vista, parece como si la gestión indirecta no fuese preferente, ya que sólo a la directa se le reservan además determinados servicios ${ }^{25}$. Sin embargo, en rigor, los servicios que se reservan a la gestión directa, incluidos los que no tengan un contenido económico (según el art. 155.1 de la Ley de Contratos), no son tales servicios, sino funciones públicas. Primero, porque todos los servicios tienen un contenido económico equivalente y, segundo, porque, si no lo tienen, será porque encajan en el concepto de función pública, del mismo modo que aquellos servicios que impliquen ejercicio de autoridad, a tenor de lo dispuesto por el artículo 92.2 de la Ley básica local ${ }^{26}$, así como en el senti-

\footnotetext{
${ }^{23}$ Vid. F. Sosa WaGner, La gestión de los servicios públicos locales, Civitas, Madrid 1999, p. 53 y ss.

${ }^{24}$ Ibid., p. 55.

${ }^{25}$ En tal sentido, el art. 114.1 del Reglamento estatal de Servicios, de 1955, establece que podrán prestarse por concesión los servicios de competencia local, salvo en los casos en que esté ordenada la gestión directa.

${ }^{26}$ Este precepto establece: «Son funciones públicas, (...), las que impliquen ejercicio de la autoridad, las de fe pública y asesoramiento legal preceptivo, las de control y fiscalización interna de la
} 
do explicitado por el artículo 189.1 del Reglamento catalán de servicios, cuando dispone:

«Los servicios que comporten el ejercicio de potestades indeclinables y de coacción administrativa deberán ser prestados por la Entidad local en la forma de gestión directa».

De ahí que la remisión a la gestión directa de tales preceptos no pueda ser interpretada como una preferencia por esta forma de gestión en determinados servicios públicos, porque, en rigor, se refiere a funciones públicas. Por ello, en dichos preceptos se contiene una doble posibilidad para gestionar los servicios públicos, cuya aplicación deberá efectuarse a la luz de la propia Constitución, de la que se desprende ese principio en favor de la libertad que comporta, necesariamente, la preferencia por la gestión indirecta siempre que sea posible, con arreglo a los artículos 9.2, 10.1 y 38 del Texto constitucional.

Por otra parte, este principio en favor de la libertad se confirma y refleja también, en el artículo 138 del Reglamento catalán de obras, actividades y servicios, cuando establece el respeto al principio de libre concurrencia, como una condición que delimita la propia iniciativa económica de las Entidades locales. La finalidad de dicha iniciativa podrá consistir tanto en la dación de bienes al mercado, como en la prestación de servicios públicos locales; y, en este caso, supondrá una gestión directa de tales servicios y en concurrencia con la iniciativa privada, a la que deberá respetar, según este precepto, como conditio sine qua non de su propia existencia. Además, esa iniciativa económica deberá estar suficientemente justificada, como exige el principio de subsidiariedad ${ }^{27}$.

En segundo lugar, ya con respecto a este principio, entendido en su sentido horizontal ${ }^{28}$, aparece como una consecuencia ineludible del principio

gestión económico-financiera y presupuestaria, las contabilidad y tesorería y, en general, aquellas que, en desarrollo de la presente Ley, se reserven a los funcionarios para la mejor garantía de la objetividad, imparcialidad e independencia en el ejercicio de la función».

${ }^{27}$ Este principio de subsidiariedad se refleja también en el art. 96 del Real Decreto 781/1986 y en el art. 31.1 del Reglamento estatal del servicios, donde se vincula además al principio de proporcionalidad, aunque ambos preceptos no se refieran ya a la elección de la forma de gestión, sino a la asunción misma de la actividad prestacional. El artículo del Reglamento dispone: «Con el fin de atender las necesidades de sus administrados, las Corporaciones locales prestarán los servicios adecuados para satisfacerlas». La cursiva es mía, para subrayar la operatividad de tales principios; es decir, que tienen que existir esas necesidades (subsidiariedad) y, además, los servicios tienen que ser adecuados a ellas (proporcionalidad).

${ }^{28}$ En ese sentido lo explica J.L. Martínez LóPEZ-MuÑIZ, «Servicio público, servicio universal y (...)», cit., en la Revista Andaluza (...), cit. supra, p. 30. 
pro libertate ${ }^{29}$, exigiendo la intervención pública en defecto de la actuación particular; y, por tanto, la gestión directa, cuando no sea posible la indirecta (o sea insuficiente). Por ello, la subsidiariedad debe proyectarse también en la previsión legal de esa doble forma de gestión, en cuanto posibilidad que deberá dar prioridad a la iniciativa particular, siempre que ésta exista y sea viable, sobre la base de los mismos preceptos constitucionales ya citados, entendidos como límite - y fundamento a la vez- de la intervención pública directa que prevé el artículo 128.2 de la propia Constitución.

Finalmente, por lo que se refiere a esta preferencia normativa de la gestión indirecta, para justificarla, antes de la reforma de la legislación de contratos por la Ley 13/1995, no era necesario recurrir a los citados principios constitucionales, por cuanto era la consecuncia inmediata del principio legal del contratista interpuesto, que se mantiene hoy implícitamente, sobre la base de la regulación de los supuestos legales en que, por excepción, procede la ejecución directa por la propia Administración de las obras públicas (siendo la regla general, por tanto, su contratación) ${ }^{30}$.

En aquel contexto, se daba la circunstancia de que la regulación del contrato de obra pública era supletoria con respecto al resto de los contratos administrativos que regulaba la Ley, por lo que la previsión misma del contrato de gestión de servicios públicos podía, por sí sola, ser entendida como la regla general para la prestación de servicios.

C) Con respecto a las modalidades del contrato de gestión de servicios públicos pueden destacarse, entre otros, dos aspectos: por una parte, su significado y su tipología en la legislación básica de contratos; y, por otra, la mayor amplitud de sus tipos en la legislación local, con el problema añadido, en la legislación estatal, de la distinción entre la concesión de servicios y el arrendamiento de instalaciones para la prestación se servicios públicos.

1. Al regular el contrato de gestión de servicios públicos, la Ley básica de Contratos establece una serie de modalidades contractuales, que se diferencian entre sí por razón de las distintas formas en que la Administración encomienda o transfiere su actividad prestacional al contratista, sin perjuicio de que todas ellas confluyan genéricamente sobre un mismo objeto, que es la gestión de un servicio público ${ }^{31}$. Sin embargo, ello ha lle-

\footnotetext{
${ }^{29}$ Puede encontrarse otra visión de este principio de subsidiariedad, entre otros autores, en J.L. RIVERO YSERn, ibid., p. 382.

${ }^{30}$ Cfr. los arts. 152 y 153 de la vigente Ley de Contratos de las Administraciones Públicas.

${ }^{31}$ Entendido en ese sentido amplio, ya expuesto.
} 
vado a la doctrina a afirmar que este contrato de gestión de servicios públicos no es una figura contractual única, sino que bajo su rúbrica «se encubre una pluralidad diversa de técnicas contractuales» ${ }^{32}$.

Por el contrario, se podrá sostener también que dicha rúbrica responde a un tipo contractual definido - aunque genérico-, que se diferencia del resto de los contratos administrativos igual que los demás, justamente en razón de su objeto; lo cual puede tener cierta trascendencia práctica, a efectos de la calificación jurídica de determinados tipos contractuales y, en consecuencia, a efectos de la determinación de su régimen jurídico, como se verá más adelante.

El objeto de este contrato, como el de todo contrato administrativo, tiende a satisfacer directamente una finalidad pública de la específica competencia del órgano de contratación que, en este caso, consiste en satisfacer las prestaciones propias del servicio público de que se trate. Por ello, el contratista asume la actividad prestacional en lugar de la Administración y en virtud del contrato. Pues bien, las distintas formas, en que la Administración articula esa colaboración del contratista, son las modalidades del contrato de gestión de servicios públicos, cuyo régimen jurídico difiere también en razón del distinto alcance de dicha colaboración.

Como es sabido, el artículo 156 de la Ley básica de contratos establece cuatro modalidades: la concesión, la gestión interesada, el concierto y la sociedad de economía mixta. En función de la naturaleza del riesgo que asuma en cada una de ellas el contratista, será también el régimen jurídico que les resulte aplicable, sin perjuicio de las prerrogativas propias de la Administración cuando celebra contratos administrativos y de las garantías equivalentes del contratista, que modulan el principio general del riesgo y ventura (establecido hoy en el art. 98 de la Ley básica de contratos). Dicho riesgo podrá ser: total, compartido, atenuado o limitado, como se podrá observar en cada una de las modalidades recordadas.

En efecto, mientras en la concesión el contratista gestiona el servicio por su cuenta y riesgo, en la gestión interesada el contratista gestiona el servicio en colaboración con la Administración que, por ello, participa de los resultados de la explotación, en la proporción que se establezca en el contrato $^{33}$. Por su parte, en el concierto el contratista (la persona natural o jurídica que gestiona el servicio) asume un riesgo atenuado, ya que viene

\footnotetext{
32 Vid. E. García de Enterría y T. R. Fernández Rodríguez, Curso de Derecho Administrativo, Civitas, Madrid 1999, p. 711.

${ }^{33}$ Vid. F. Sosa Wagner, Manual de Derecho local, cit., p. 233.
} 
realizando prestaciones análogas a las que constituyen el servicio público de que se trata; y, finalmente, en la sociedad de economía mixta, la Administración asume un riesgo limitado ${ }^{34}$, mediante su participación minoritaria en la sociedad gestora ${ }^{35}$.

2. Todas estas modalidades se establecen también para el ámbito local en el artículo 85.4 de su Ley básica que, además, dispone la figura del arrendamiento y la de la sociedad cooperativa. Ambas aparecen también en los preceptos concordantes de la legislación estatal y autonómica. Estas figuras típicamente locales pueden plantear algunas dudas.

Una primera cuestión sería la de si la legislación básica y general de contratos ha limitado o no las distintas modalidades de gestión de los servicios públicos; es decir, si caben o no otras modalidades, como las ya apuntadas, fuera de dicha Ley básica de contratos. La respuesta parece que debe ser positiva, ya que las normas sobre contratación en el ámbito local gozan de la condición de normas especiales, frente a la legislación general de contratos, en razón justamente de la especial naturaleza de las Administraciones contratantes. Por tanto, como la ley especial deroga la ley general, no debe haber ningún obstáculo para admitir esas modalidades contractuales en el ámbito local.

Una segunda cuestión sería la de si caben o no otras modalidades contractuales de la gestión de servicios públicos en el ámbito local, al margen de las señaladas ya por la propia Ley básica local; la cuestión ha sido resuelta por la doctrina en sentido afirmativo, como una consecuencia del principio de autoorganización de las Corporaciones locales que, según el Tribunal Constitucional, es la más significada seña de identidad de su autonomía $^{36}$.

La tercera cuestión sería la de dar un contenido específico a uno de los tipos de la figura del arrendamiento, que viene previsto como una modalidad contractual típica del régimen local. Este contrato se contempla en el artículo 95.2 del Texto Refundido del Régimen local y se regula en los artículos 138 a 142 del Reglamento estatal de servicios de 1955; además, en la legislación catalana aparece regulado en los artículos 245 y 246 de su

\footnotetext{
34 Por sí misma o por medio de una Entidad pública instrumental, según se establece en el art. 156,d) de la Ley básica de contratos.

${ }^{35}$ Como es sabido, en la sociedad de economía mixta la participación de la Administración deberá ser minoritaria, so pena de dejar de ser una modalidad de gestión indirecta y convertirse en una gestión directa.
}

36 Vid. F. Sosa WaGener, La gestión de los servicios..., cit., pp. 57-58. 
Ley local y en los artículos 275 a 281 de su Reglamento de servicios. No se plantea el mismo problema en esta legislación catalana, donde el arrendamiento tiene un significado más preciso, aunque quizás algo incompleto.

Como punto de partida, tanto en el ámbito estatal como en el autonómico, sólo podrán ser objeto de arrendamiento los servicios locales cuyas instalaciones pertenezcan a la Corporación. La regulación estatal define como arrendamiento tres supuestos diferentes: 1) el arrendamiento de instalaciones de la Entidad para la prestación de un servicio; 2) los servicios en los que el gestor se comprometa a aportar los medios materiales y personales necesarios; y, 3) los servicios personales y transitorios a la Entidad. Este último supuesto ha de entenderse derogado desde la Ley 30/1984, que establece la prohibición general de los contratos administrativos para el personal al servicio de las Administraciones públicas ${ }^{37}$ y es el único de los tres que no aparece en la legislación catalana.

El segundo supuesto aparece previsto en la legislación estatal y también en la catalana, de manera similar; se parece mucho al contrato de servicios del artículo 196.3 del Texto Refundido de contratos de las Administraciones Públicas. Sin embargo, no coincide con él precisamente por razón del objeto del contrato de gestión de servicios públicos, que comporta necesariamente prestaciones al público, mientras que los contratos de servicios articulan prestaciones en favor de la Administración, de las que se sirve instrumentalmente para el ejercicio de sus funciones.

La propia regulación de esta figura demuestra que es un auténtico contrato de gestión de servicios públicos, cuando en ella se prohíbe que la contraprestación, en favor del gestor del servicio, pueda consistir en la percepción de precios o tasas de los usuarios (que son los destinatarios del servicio), previendo su abono directo por la Corporación. Así se establece tanto en el artículo 141 del Reglamento de servicios estatal, como en el artículo 281.3 del Reglamento catalán. Aparentemente, éste es el único tipo de arrendamiento con un sentido propio y específico en la regulación estatal, en cuanto modalidad del contrato de gestión de servicios.

Por su parte, el primer tipo de arrendamiento viene a coincidir en la regulación estatal con uno de los posibles tipos de la modalidad contractual de la concesión de servicios. Ésta podrá consistir en una concesión mixta, cuando comporte la gestión del servicio y la previa construcción de las obras necesarias para ello (coincidiendo entonces con una de las posi-

${ }^{37}$ Vid. F. Sosa Wagner, La gestión de los servicios..., cit., p. 190. 
bles modalidades de concesión de obra pública ${ }^{38}$ ), o en una concesión simple, cuando suponga la mera gestión de un servicio, bien que no requiera instalaciones permanentes o bien que éstas ya estuvieran debidamente establecidas.

Como puede verse, este tipo de arrendamiento parece coincidir plenamente con el segundo caso de la simple concesión de servicios públicos y, en principio (de no encontrar un criterio de distinción), debería regirse por sus mismas reglas y por las que la Ley básica establece específicamente para los contratos de gestión de servicios públicos ${ }^{39}$; aunque, como se indica enseguida, esa coincidencia no es del todo plena.

Primero, porque la figura del arrendamiento se plantea en la legislación local con un criterio económico, cuando suponga un ahorro o un beneficio para la Corporación, según se desprende del artículo 138.3 del Reglamento estatal de servicios; nada se dice en este sentido, sin embargo, en la legislación catalana, aunque parece confirmarlo, cuando excluye del arrendamiento los servicios de asistencia social (art. 245.2 de la Ley local catalana) ${ }^{40}$. Y, segundo, porque su utilización tiene consecuencias de régimen jurídico que pasan por los efectos propios del arrendamiento del bien para la prestación del servicio.

Ello supone que habrá que recurrir al arrendamiento, por ejemplo, siempre que la Entidad tenga las instalaciones a punto, para que el contrato de gestión reporte como beneficio el canon que deba abonar el arrendatario gestor del servicio. En otro caso, cuando el bien no esté a punto, recurrir al arrendamiento, podría evitar el encarecimiento de la concesión del servicio, como consecuencia del coste de rehabilitación de las instalaciones que debieran estar adscritas a ella; pues, en todo caso, la Administración tendría que abonar su importe al concesionario y ese coste se lo podría ahorrar, optando por el arrendamiento, compensándolo con el canon que debiera abonar el arrendatario ${ }^{41}$.

\footnotetext{
${ }^{38}$ Tal y como se define en el art. 220 del Texto Refundido de la Ley de Contratos de las Administraciones Públicas, tras ser modificado por la Ley 13/2003, reguladora del Contrato de Concesión de Obras Públicas.

${ }^{39}$ Sin embargo, se ha sostenido que al arrendamiento no le resultan aplicables las reglas específicas que, sobre los contratos de gestión de servicios públicos, se establecen por la Ley básica de contratos; vid., en este sentido, F. SOSA WAGNER, La gestión de los servicios..., cit., p. 185.

${ }^{40}$ Exclusión que se desprende también, expresamente, del art. 138.2 del Reglamento estatal de Servicios de 1955.

${ }^{41}$ Con todo, a partir del 24 de agosto del 2003 en que entrará en vigor la Ley reguladora del contrato de concesión de obras públicas (Ley 13/2003), tal vez, deba plantearse también la diferencia
} 
En consecuencia, en principio, el criterio de distinción es puramente económico. Aunque no sólo, pues, en la práctica, la utilización del arrendamiento se va a proyectar también en los efectos propios del régimen de la gestión del servicio público; así, esa proyección se va a traducir en una vinculación menos intensa del arrendatario con la Administración concedente del servicio, que la propia del concesionario (en la misma línea apuntada por Mestre Delgado) ${ }^{42}$. Esa menor intensidad en la colaboración del contratista es el resultado de la incidencia en la gestión del servicio del arrendamiento instrumental del bien.

Así, las consecuencias jurídicas del arrendamiento van a proyectarse en la situación del gestor frente a la Administración, modulándola con la lógica propia de la posición del arrendatario; esta lógica impedirá, por ejemplo, que la Administración pueda ordenar al arrendatario la realización de obras necesarias en el bien adscrito a la prestación del servicio ${ }^{43}$. Esto hará que el arrendamiento aparezca como una figura menos adecuada que la concesión, cuando la gestión del servicio público se refiera a actividades reservadas; pues, en tales casos, los criterios primordialmente económicos deberían ceder, ante una mejor garantía del servicio ${ }^{44}$.

Por su parte, en la legislación catalana no se plantea este problema de interpretación, pues, en ella, se ha recurrido a la medida de excluir de la concesión simple el supuesto de la gestión del servicio con instalaciones de la Corporación, al disponer que en este tipo de concesión el concesionario aportará siempre los medios materiales, personales y técnicos para la gestión del servicio (según el art. 241 de la Ley local catalana); lo cual impide ya su coincidencia con el arrendamiento.

Sin embargo, a pesar de lo plausible de su precisión, esta legislación plantea el siguiente problema: los bienes que pertenezcan a la Corporación, por reversión, una vez concluida la concesión a la que estén adscritos, qué papel juegan. ¿Supone esto que la Corporación entonces sólo

efectiva entre este arrendamiento y la concesión de obra pública (a la luz del nuevo art. 220 de la Ley de Contratos de las Administraciones Públicas).

${ }^{42}$ Vid. J.F. Mestre Delgado, «Las formas de prestación de los servicios públicos locales. En particular, la concesión», en Tratado de Derecho Municipal (Dir. S. Muñoz Machado), II, Civitas, Madrid 1998, p. 1244.

${ }^{43}$ Como lo confirma una Sentencia del Tribunal Supremo, de 15 de febrero de 1999 (Cfr. Aranza$d i, 915 / 1999)$.

${ }^{44}$ Esta idea viene confirmada por el ya citado art. 138.3 del Reglamento estatal de servicios, al referirse a la conveniencia de la utilización del arrendamiento, «cuando se hubieren de tener primordialmente en cuenta los intereses económicos de la Corporación». 
podrá arrendar el servicio? y, si es así, ¿no supone una mayor garantía el régimen de la concesión que el del arrendamiento? ${ }^{45}$.

II.- Por último, como ya se indicó al principio, a la gestión indirecta de los servicios públicos locales también se refieren los convenios ${ }^{46}$, entendidos como contratos interadministrativos de cooperación. En tal caso, al menos, una de las Administraciones contratantes será una Entidad local, en razón de su propia competencia con respecto al servicio público de que se trate. Parece, además, que deberá tratarse de una competencia no exclusiva, la que justifique dicha cooperación, según cabe deducir de lo dispuesto en el artículo 57.1 de la Ley básica local, cuando establece:

«La cooperación económica, técnica y administrativa entre la Administración Local y las Administraciones del Estado y de las Comunidades Autónomas, tanto en servicios locales como en asuntos de interés común, se desarrollará con carácter voluntario, bajo las formas y en los términos previstos en las leyes, pudiendo tener lugar, en todo caso, mediante los consorcios o convenios administrativos que suscriban.»

Se podrá afirmar, así, que el ámbito propio de tales convenios se corresponde con el de algunas competencias no exclusivas ${ }^{47}$, las compartidas y las abiertas o indistintas de las Corporaciones locales ${ }^{48}$, con respecto a las de otras Entidades públicas. En tal sentido, por competencias compartidas habrá que entender aquéllas que consistan en distintas funciones sobre las mismas materias (como sucede, por ejemplo, con el servicio de transporte público de viajeros); mientras que, por competencias abiertas o indistintas, habrá que entender las que consistan en las mismas funciones sobre las mismas materias (como sucede con los servicios culturales, en los distintos niveles territoriales).

Por otra parte, en cuanto a la regulación de tales convenios, dicho artículo 57 se remite a «las formas y en los términos previstos en las leyes». De este modo, para el caso de los convenios entre los Entes locales y el Estado o una Comunidad Autónoma, el artículo 9 de la Ley 30/1992 se remite, a su vez, a la legislación local y, con carácter supletorio, a lo esta-

\footnotetext{
${ }^{45}$ Tal vez se pueda recurrir, entonces, a la concesión de obra pública pública, tal y como se regula en la nueva Ley 13/2003.

46 Vid. Lliset BorRel, «Los convenios interadministrativos de los Entes locales», en Revista Española de Derecho Administrativo, 67 (1990), pp. 389-398.

47 Vid. J. A. García-Trevijano Fos, Tratado de Derecho Administrativo, II, Revista de Derecho Privado, Madrid 1967, p. 394.

${ }^{48}$ Ambas encajarían en la noción de competencias concurrentes; vid. J. L. MARTínEz LóPEZ-MuÑIZ, Los consorcios en el Derecho español, I.E.A.L., Madrid 1974, p. 295.
} 
blecido en su propio Título I (en concreto, será especialmente relevante lo dispuesto en el art. 6).

En este punto, hay que destacar la importancia de la regulación contenida en los artículos 303 a 311 del Reglamento catalán de Servicios, cuya normativa desarrolla el citado artículo 57 de la Ley básica local, refiriendo estos convenios a las Entidades locales entre sí, o a los que celebren éstas con otras Entidades públicas. Tales preceptos confirman la naturaleza propiamente contractual de estos convenios, al establecer que se regularán en primer término por sus propias cláusulas y, además, que las partes del convenio actuarán en pie de igualdad (sin que ninguna de ellas pueda ejercitar potestades ejecutivas o coactivas frente a las restantes) ${ }^{49}$.

Cabe subrayar, finalmente, que la posición de igualdad de las Entidades parte en estos convenios, permite que puedan articular encomiendas de gestión, de las previstas por el artículo 15 de la Ley 30/1992; pues tales encomiendas sólo suponen una transferencia de actividades de carácter material, técnico o de servicios (por razones de eficacia o cuando no se posean los medios técnicos idóneos para ello), sin que la Entidad encomendante renuncie en ningún momento a su competencia.

\footnotetext{
${ }^{49}$ Cfr. el art. 304.1 del Reglamento obras, actividades y servicios de las Entidades locales de Cata-
} luña. 